\title{
Socialização em Fóruns Virtuais - Proposta Pedagógica para Cursos de Formação de Docentes na Modalidade Semipresencial
}

\section{Socialization in Virtual Forums - a Pedagogical Approach for Teacher Training Courses in Blended Learning Mode}

\author{
Paula Patrícia Barbosa Ventura \\ Instituto Federal de Educação, Ciência e Tecnologia do Ceará
}

\begin{abstract}
Resumo: O objetivo desse artigo é descrever a proposta pedagógica adotada numa instituição de ensino superior que utiliza a modalidade semipresencial como alternativa para promover aprendizagem formal. No aporte teórico, utilizou-se autores como: Brym et al (2006), Giddens (2005), Piaget (1973), Becker (1994), Behar,Kist e Schneider (2004), Vasconcelos (1995), dentre outros. A metodologia, caracterizada como participativa (CHIZZOTTI, 2014), privilegiou a cooperação online, tomando por base a interação entre os participantes, especificamente na vivência docente dos alunos-professores em serviço. Apesar de o público-alvo ser bastante heterogêneo (de diversas áreas do conhecimento), o diferencial esteve nas ações tutoriais, dentre elas, na postura provocativa e investigativa da professora-tutora. Como contribuição, a proposta pedagógica mostrou alternativas positivas de serem trabalhadas com professores em serviço, tais como: a desconstrução das certezas professorais, através da socialização das práticas e do conhecimento teórico-prático das interações interindividuais; o incentivo à pesquisa, possibilitando o aluno-professor a (re)pensar os métodos de ensino utilizados; o exercício da autoria e co-autoria, incentivando a valorização das ideias discentes e, sobretudo, os processos avaliativos num curso semipresencial. O sucesso da proposta se deu à utilização de um planejamento flexível, de familiaridade e aprofundamento teórico com o objeto a ser trabalhado, pois o importante quando se utilizam determinadas propostas, é privilegiar a problematização, a cooperação e os saberes construídos em conjunto, todos eles fundamentados em uma concepção epistemológica progressista de educação.
\end{abstract}

Palavras-Chave: Proposta Pedagógica, Educação Semipresencial, Cooperação,Formação de Docentes em Serviço.

Abstract: This article's main goal is to describe the pedagogical approach adopted in a higher education institution which uses blended learning as an alternative to promote formal learning. Regarding the theoretical framework, the authors studied were: Brym et al (2006), Giddens (2005), Piaget (1973), Becker (1994), Behar, Kist and Schneider (2004), Vasconcelos (1995), among others. The methodology, characterized as participatory (CHIZZOTTI, 2014), focuses on online cooperation, based on the interaction between the participants, more specifically on the teaching experience of working student-teachers. Although the target audience is very heterogeneous (from various fields of knowledge), the difference was in the tutoring actions, and among them, the instigative and investigative attitude of the tutor-teacher. As a contribution, the pedagogic proposal showed positive alternatives to be performed with working teachers, such as: the deconstruction of teaching certainties, through the socialization practices and the theoretical-practical knowledge of interpersonal interactions; research incentive, enabling the student-teacher to (re) think the teaching methods used; the exercise of authorship and co-authorship, encouraging the appreciation of the students' ideas and, above all, the evaluation processes in a blended course. The proposal was successful thanks to the 
use of flexible planning, conversance and theoretical study with the object being worked upon, for what's important when using certain proposals is to highlight the questioning, the cooperation and the knowledge all together, for all of them are based on a progressive epistemological framing of education.

Keywords: Pedagogical Approach, Blended Education, Cooperation, Working Teacher Training.

VENTURA, Paula Patrícia Barbosa Ventura. Socialização em Fóruns Virtuais - Proposta Pedagógica para Cursos de Formação de Docentes na Modalidade Semipresencial. Informática na Educação: teoria \& prática, Porto Alegre, v. 19, n. 3, p. 50-69, set./dez. 2016.

\section{Introdução}

A utilização das tecnologias digitais na educação trouxe oportunidades diferenciadas de comunicação e expressão, ao mesmo tempo que provocou novas formas de pensar e (re)estruturar o conhecimento. Kenski (2013) argumenta que é necessário discutir propostas que transcendam os limites físicos e temporais das salas de aulas, alcançando pessoas que querem, têm interesse e estão conectadas na mesma sintonia, independente do tempo e espaço que se encontram. Destarte, é preciso deixar de lado metodologias que privilegiam a aquisição de conteúdos descontextualizados, rígidos e fragmentados em torno de temas que não dialogam entre si.

Especificamente nos cursos de formação de professores, a autora (op.cit) destaca que o problema reside não só em metodologias que privilegiam a estrutura disciplinar e a formação intelectual dos alunos, além da pouca integração e inter-relação entre as disciplinas teóricas, caracterizadas como fundamentos da formação docente, e as disciplinas que privilegiam os aspectos didáticos metodológicos, mas sim na pouca autonomia do professor em relação à definição de conteúdos e procedimentos pedagógicos.

Ainda que se cumpraliteralmente o programa da disciplina, o docente deve (re)significar sua prática e hábitos professorais, aprendendo a trabalhar pedagogicamente e de forma dinâmica e desafiadora, independente da modalidade educacional. Nesse sentido, o objetivo desse artigo é descrever a proposta pedagógica adotada na Faculdade Integrada da Grande Fortaleza (FGF), uma instituição particular de ensino superior, que utiliza a modalidade semipresencial como alternativa para promover aprendizagem formal, no curso intitulado Formação Pedagógica de Docentes para professores em serviço.

A proposta utilizada vai ao encontro das ideias de Behar (2004), ao afirmar que a educação precisa se reorganizar para incluir em seu processo educativo uma pedagogia, metodologias, técnicas e recursos que permitam um novo paradigma que substitua a competição (alienante e individualizante) pela cooperação entre os sujeitos e a necessidade do físico pelo virtual. Mais enfaticamente, sugere-se a utilização da ferramentafórum para socializar as práticas dos alunos-professores, bem como as dúvidas, sendo a comunicação virtual a peça-chave para eliminar distâncias, estreitar as relações interindividuais e redefinir o perfil de profissionais que desejam aprender de forma não convencional em relação ao modelo adotado em instituições de 
formação superior. A forma convencional está relacionada à presença física em instituições e a cronogramas predefinidos, o que implica deslocamento de professores e alunos.

Para atingir o objetivo, o artigo está dividido em cincoseções. Após as considerações introdutórias, na segunda seçãosãoexpostasalgumas ideias históricas e contemporâneas sobre o fórum de discussão, bem como o processo de socialização online. Em seguida, é descrita a estrutura curricular dos cursos de formação pedagógica de docentes da FGF. Posteriormente, são abordadasa metodologia, o referencial teórico da proposta pedagógica, bem como sua descrição e análise. Por último, algumas considerações são feitas.

\section{Fórum de Discussão: algumas ideias históricas e contemporâneas}

O fórum remete à ideia de fórum de discussão virtual, digital ou online, mas a expressão "fórum de discussão"é mais antiga. Segundo Brito (2004), o fórum evoca as grandes assembleias romanas, em que as pessoas se reuniam para debater sobre um tema ou problema determinado, com a finalidade de permitir a livre expressão de ideias e opiniões. 0 fórum exige um mínimo de normas às quais todos os participantes devem se ajustar, dentre elas destacar-se, expressar-se com objetividade e centrar-se no problema.

A utilização do fórum pode trazer benefícios para todos, desde que os objetivos dos participantes coadunem entre si. Tais benefícios são: obter-se opiniões de um grupo mais ou menos numeroso acerca de um tema, problema ou atividade; chegar a conclusões gerais; incrementar a informação dos participantes através de múltiplas opiniões e desenvolver o espírito participativo dos membros (BRITO, 2004).

O autor (op.cit.) destaca também que a participação do moderador do grupo é essencial para o desenvolvimento das discussões. Este deve possuir habilidade e rapidez em suas ações; ser prudente e diplomático em certas circunstâncias; cordial em todo momento; sereno; seguro de si mesmo; estimular a participação do grupo; possuirsenso de humor e, por último, apresentar o objetivo da discussão, estimular e dirigir as intervenções, finalizar com uma síntese e apresentarconclusões.

No caso dos fórunsvirtuais educacionais (estudado como gênero e suporte da educação online), destaca-se que sua função principal é:

[...] constituir-se espaço para a discussão de um tema. Como o tema é combinado, o fórum digital educacional oferece condições para a construção de um ambiente colaborativo, em que o conhecimento é construído coletivamente por diferentes interlocutores e compartilhado para a construção ou a reconfiguração de conceitos (SILVA, 2009, p. 48).

Consoante esse pensamento, para que haja espírito coletivo, a linguagem utilizada deve ser clara e de fácil entendimento, já que o fórum potencializa inúmeras interpretações acerca do objeto cognoscível/cognoscente. Por possuir natureza muldimensional, há uma similaridade de papeis entre professor-tutor ${ }^{5}$ e alunos (VENTURA, 2009).

${ }^{5}$ Denomina-se professor-tutor ou tutor a distância o profissional que tem formação em nível superior, participa do planejamento da disciplina, além de realizar a interface com o aluno, acompanhando-o nas atividades a distância. Desloca- 
Como o fórum se caracteriza pela assincronicidade, Matta (2003) ressalta que esse tipo de ferramenta proporciona um tempo maior para a reflexão e elaboração das mensagens, aspecto de grande importância em atividades de caráter educacional. Além disso, para facilitar a socialização de práticas e dúvidasentre os participantes, é preciso compreender pedagogicamente que este tipo de ferramenta permite ampliar a discussão(um-um, um-todos; todos-todos); questionar no sentido de chamar a atenção para o que, de fato, é importante ou o que pode ser priorizado em seus argumentos para movimentar a discussão; sugerir que outros alunos comentem uma determinada colocação; aconselhar leituras complementares e links sobre o assunto abordado; permitir que os próprios alunos discutam durante algum tempo antes de comentar as mensagens; orientar os alunos em relação ao tempo e datas dos fóruns de discussão. Neste último caso, o e-mail (mensagem individual) é mais viável, pois a orientação fugiria do objetivo do fórum.

Para tanto, o fórum deve ser visto como uma ferramenta didático-pedagógica que possibilita,além da interação e integraçãoentre os participantes, a socialização, promovendo a autonomia dos aprendizes, uma vez que cada um é responsável pela aprendizagem mútua e não deve ser visto apenas como um espaço onde se depositam opiniões. Se não houver uma proposta definida, objetivos claros e coerentes com o tipo de metodologia proposta, assim como a valorização das trocas dialógicas, e a intervenção do professor ao longo de todo o processo inclusive no feedback ou na devolutiva do processo avaliativo, não haverá uma aprendizagem cooperativa.

Como citado em parágrafos anteriores, uma das características do fórum é suscitar a socialização entre os participantes, termo definido a seguir e correlacionado ao fórum de discussão virtual.

\subsection{Socialização em Fóruns Virtuais}

O termo socialização, é definido por Brym et al (2006) como o processo pelo qual as pessoas aprendem a sua cultura. O termo advém do vocábulo social e remete a palavras como sociedade, cultura, indivíduo, valores e princípios. Assim, pode-se dizer que o indivíduo aprende a ser membro de uma sociedade, de uma comunidade e, mais especificamente, de um grupo, valorizando certos ideais e assumindo determinados papeis e funções. Os autores (op.cit) destacam dois elementos para se compreender o processo de socialização entre as pessoas. Primeiro, adotam e abandonam uma série de papeis e, segundo, tornam-se conscientes de si próprias enquanto interagem com os outros.

Giddens (2005) enfatiza que a socialização é um processo que dura por toda a vida, sendo modelada constantemente pelas interações sociais. Segundo o autor (op.cit), além da cultura do indivíduo, a socialização está também na origem da individualidade e liberdade. Ou seja,

se aos polos para ministrar aulas por ocasião dos encontros presenciais. Executa metodologias de avaliação, aplica e corrige as provas. 
cada pessoa desenvolveum sentido de identidade, formas de pensar e modos de agir, fazendo com que assumam posições ativas e ocupem papeis sociais por meio das interações. Provavelmente tais características reflitamna personalidade, valores e comportamentos humanos.

Silva (2012b, p. 203) ao discutir a socialização presencial e a distância questiona:

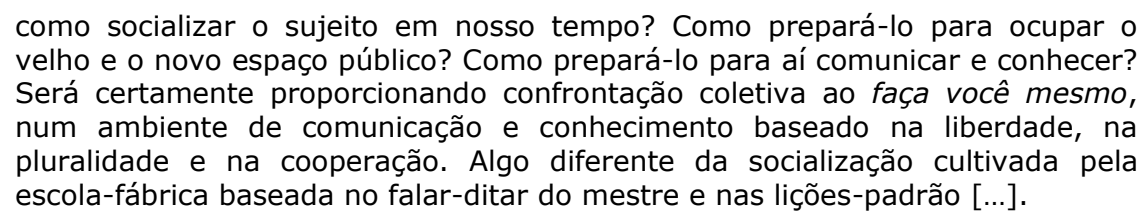

Ao mesmo tempo que o autor (op.cit) lança esse questionamento, responde afirmando que a socialização deve ser baseada na comunicação e no conhecimento em confrontação coletiva. Põe em pauta a liberdade e diversidade do docente, sendo este responsável pelo diálogo criativo entre as competências individuais.

Especificamente no fórum de discussãovirtual, a socialização exige que os indivíduos aprendam a cultura online, as formas de comunicação (um-um; um-muitos; muitos-muitos) e interação (colaborativa e cooperativa) e controlem seus impulsos e emoções, bem como reflitam sobre seus processos cognitivos e de aprendizagem.

Por meio de ferramentas online, as pessoas materializam um pensamento real e, ao mesmo tempo, simbólico constantemente interconectado à reflexão do outro, capaz de produzir sentido e não apenas um pensamento ligado ao que é visível e sensível ao toque, ao cheiro e ao olhar etc., interações restritas aos órgãos dos sentidos.Permite também aprender a cultura do outro, a apreender a forma como este outro se comunica, interage e expõe seus pensamentos (de forma organizada, sistematizada devido ao tempo maior de síntese das ideias, característica do fórum de discussão), possibilitando imaginar como essas pessoas são e se comportam na presencialidade.

Para que a socialização em fóruns virtuais seja eficaz, os participantes devem ter ciência das especificidades da modalidade onlinee desta ferramentaassíncrona.

Na seção seguinte, será relatada a estrutura curricular dos cursos de formação pedagógica de docentes da instituição analisada.

\section{Estrutura Curricular dos Cursos de Formação Pedagógica de Docentes da Faculdade Integrada da Grande Fortaleza (FGF)}

A FGF tem desenvolvido importantes iniciativas na área de Educação Online, dentre elas a formação de professores. Sua missão é formar o cidadão através da educação, habilitando profissionais em nível superior, empreendedores, reconhecidamente competentes, reflexivos, críticos, éticos e com responsabilidade social(FGF, online). Nessa perspectiva, a instituição oferece cursos de extensão, graduação, sequenciais, licenciatura e pós-graduação na modalidade semipresencial. 
Especificamente nas licenciaturas, há o Programa Especial de Formação Pedagógica de Docentes nas áreas de Arte-Educação, Biologia, Física, Matemática, Português e suas Literaturas e Química. Este programa destina-se a suprir a falta de professores habilitados nas escolas, em determinadas disciplinas e localidades, em caráter especial. São destinados a portadores de diploma de nível superior, que tenham sólida base de conhecimentos na área de estudos ligados a essa habilitação. O objetivo desses cursos é formar pedagogicamente profissionais portadores de diploma de Programa Superior, para atuarem como professores na área do Ensino Fundamental, Médio e Profissionalizante (FGF, online).

O processo seletivo acontece em um encontro presencial no ponto de presença escolhido, no qual há a análise das habilidades técnicas do candidato na sala de aula virtual, bem como a análise curricular, em que deve constar, no mínimo, 120 horas-aula em estudos relacionados com a área da habilitação pretendida que comprovem uma consistente base de conhecimentos. O concluinte do programa especial recebe certificado e registro profissional equivalentes à licenciatura plena.

Diferente dos cursos de licenciatura ofertados em outras instituições de ensino, a FGF oferta seus cursos em módulos, com carga horária de 24h/a cada, exceto o módulo de Prática Docente Supervisionada, com 300h/a. Para os módulos de 24h/a, são vinte e oito dias na sala de aula virtual e um encontro presencial no polo de presença, onde ocorre a avaliação escrita, conforme preconiza a legislação específica para a Educação a Distância, através do Decreto no 5622/2005 (BRASIL, 2005).

Cada curso de licenciatura possui três núcleos: contextual, estrutural e integrador. O núcleo contextual corresponde aos módulos comuns a todos os cursos. O núcleo estrutural corresponde a módulos específicos de cada curso e o integrador, assim como o contextual, corresponde a todos os cursos. Em alguns cursos, como os de Biologia, Química e Física, há 24 horas da carga horária total do curso para a prática laboratorial, distribuídas em seis atividades realizadas nos momentos presenciais do Núcleo Estrutural. Para todos os cursos, a carga horária é diferenciada, sendo comum o tempo destinado à elaboração da monografia, que é de três meses.

As avaliações finais de cada módulo correspondem a $50 \%$ de atividades na sala de aula virtual e 50\% de avaliação presencial. O ambiente virtual de aprendizagem utilizado pela instituição é o TelEduc, versão 4.36. Para cada módulo,há um professor-tutor para atender a turma e sua titulação varia de graduados a doutores. Quanto ao material didático utilizado, é disponibilizado, em extensão PDF, um arquivo próprio elaborado por professores da instituição, exceto os materiais do módulo de Prática Docente Supervisionada, em que o professor-tutor tem autonomia de escolher o que julgar necessário.

A seguir, um mapa conceitual ${ }^{7}$ com o resumo da estrutura curricular dos cursos de Formação Pedagógica de Docentes da FGF.

\footnotetext{
${ }^{6}$ À época da aplicação da proposta pedagógica, a versão utilizada foi a 3.2.3.

${ }^{7}$ Estrutura esquemática para representar um conjunto de conceitos imersos numa rede de proposições. [...]. Pode ser entendido como representação visual utilizada para partilhar significados, pois explicita como o autor entende as relações entre os conceitos enunciados. O mapa conceitual se apoia fortemente na Teoria da Aprendizagem Significativa de David Ausubel, que menciona como o ser humano organiza o seu conhecimento por meio de uma hierarquização dos conceitos (TAVARES, 2007).
} 
FIGURA 1 - Mapa conceitual I

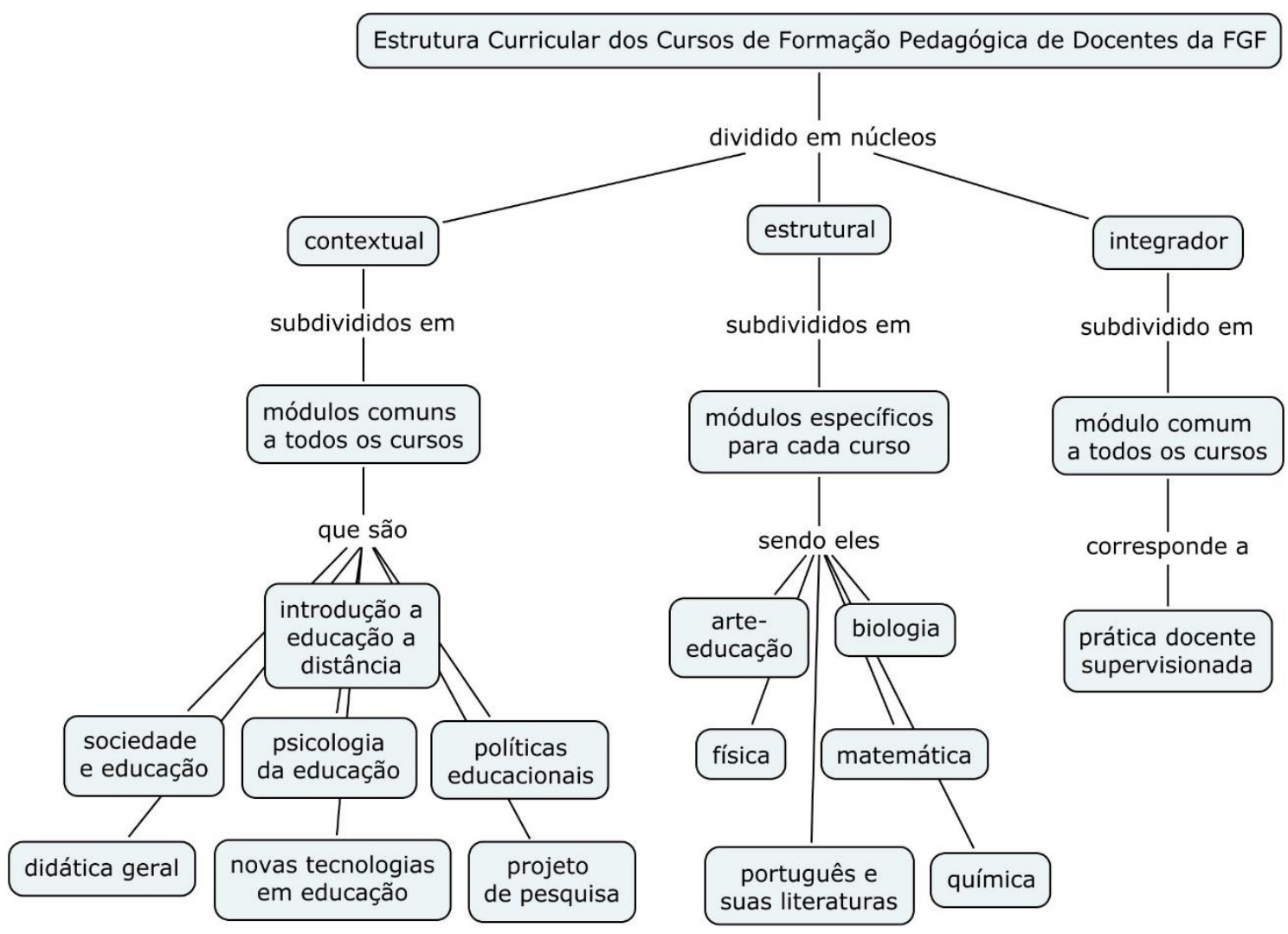

FONTE- Elaborado pela própria autora

\section{Narração Metodológica}

Visando alcançar o objetivo deste artigo, que foi descrever a proposta pedagógica adotada na FGF,instituição superior referência em educação semipresencial, que utiliza esta modalidade educacional como alternativa para promover aprendizagem formal, no curso intitulado Formação Pedagógica de Docentes para professores em serviço, a proposta se caracterizou como participativa.

Segundo Chizzotti (2014, p. 90), a pesquisa participativa tem como finalidade orientar a prática, a democratização da produção de conhecimento e da sociedade, e o desenvolvimento da justiça social, sendo que:

Não é um mero conjunto de métodos, meios e técnicas, mas se fundamenta em uma ética e em uma concepção alternativa da produção popular do conhecimento, segundo a qual as pessoas comuns são capazes de compreender e transformar sua realidade. Trata-se de um modelo e de um meio de mudança efetiva para a qual os sujeitos implicados devem elaborar e trabalhar uma estratégia de mudança social.

Esse tipo de pesquisa ressalta o caráter participativo dos envolvidos objetivando "alcançar uma outra situação e, ainda que pressuponha momentos distintos entre si, a singularidade de 
cada momento é parte de um todo, do qual todos são coautores participantes do processo de produção do conhecimento a ser incorporado na ação" (CHIZZOTTI, 2014, p. 93).

Compreende-se que a utilização desse tipo de pesquisa se deu por compreender que, embora os participantes tivessem formações acadêmicas diferenciadas, todos possuíam um saber singular e foram produtores de conhecimento, sendo as trocas comunicativas (oriundas do processo de socialização) essenciais para novas construções e aprendizagens. Por este motivo, algumas atividades foram denominadas de socializadoras, tendo em vista que os participantes, no caso os alunos-professores, se assumiram como autores conscientes de seus papeis como discentes e da necessidade de socializarem os saberes adquiridos e os que já possuíam internalizados, visando melhorarem suas práticas e posturas docentes.

Nesse sentido, o papel da pesquisadora, no caso a autora deste artigo, foi de atuar pedagogicamente, linkando as ideias dos alunos-professores e organizando as participações, bem como retroalimentando-as para que as interações fluíssem. Chizzotti (2014, p. 95) enfatiza que o papel do pesquisador nesse tipo de pesquisa é:

Garantir a interlocução dos diferentes segmentos sociais e a comunicação permanente de todos os participantes, aparando ruídos de comunicação, manipulações de informações, conflitos de interesses e de personalidades que possam ocorrer, no curso dos debates, assegurando que o processo da pesquisa é a oportunidades de formação na ação de toda a população envolvida.

Participaram do módulo de Prática Docente Supervisionada 29 dos 35 alunos regularmente matriculados no Programa Especial de Formação Pedagógica de Docentes da FGF. O critério de escolha deste módulo se deu por ele possuir uma estrutura didático-pedagógica diferenciada dos demais módulos ofertados. Diferenciada pela carga-horária, pela flexibilidade de se adaptar o planejamento às necessidades e à realidade das escolas, pela autonomia da professora-tutora na criação de atividades, assim como pela elaboração de estratégias que focassem não apenas a construção do conhecimento, mas também o desenvolvimento do aluno-professor, enquanto sujeito transformador do seu fazer docente.

A realização do módulo ocorreu no semestre 2010.2, especificamente entre os meses de agosto de 2010 a janeiro de 2011 e contou com diversas atividades, distribuídas em momentos, as quais foram divididas em: fóruns de discussão socializadores e de conteúdo e portfólios individuais. Outras atividades não estavam relacionadas aos momentos, mas constituíram atividades, como o preenchimento do perfil e um fórum denominado café da tarde. Algumas das atividades relacionadas aos momentos não possuíram pesos, pois a finalidade delas foi compartilhar interesses, experiências, dúvidas e motivar os alunos-professores, tornando uma verdadeira comunidade virtual de prática8

As atividades foram definidas com base em três elementos: um referencial teórico que fundamentasse as ações desenvolvidas pelos participantes; uma metodologia flexível e adaptável à realidade dos alunos-professores; assim como um suporte telemático, viabilizando a utilização das tecnologias digitais, já que o curso foi ofertado na modalidade semipresencial.

${ }^{8}$ As comunidades de prática são organizações que mantêm uma continuidade temporal, mas que sobretudo se definem pela partilha de uma prática entre os seus diferentes membros, mais que por ter uma ideia de comunidade muito mais definida que as comunidades virtuais esporádicas, conjunturais (ILLERA, 2007). 
E pensada especificamente para o módulo de Prática Docente Supervisionada, último módulo que a autora deste artigo atuou como professora-tutora9.

As ferramentas de comunicação mais utilizadas no ambiente virtual foram o Fórum de Discussão, Portfólio, Correio e Mural, o que constituiu o suporte telemático da proposta utilizada. Outras ferramentas foram utilizadas de acordo com a necessidade, tais como: Agenda (utilizada para explicar sucintamente as diretrizes de cada momento e foi elaborada um dia antes de cada momento), Atividade (utilizada para especificar cada atividade quando havia um roteiro específico de cada momento), Dinâmica do Curso (utilizada para explicar a estrutura do módulo), Leituras (utilizada para postagem de algum arquivo complementar), Parada Obrigatória (utilizada para divulgar as notas dos momentos), Perfil (utilizada para a apresentação dos alunos) e Acessos (para visualizar a periodicidade de acesso dos alunos ao ambiente).

\subsection{Referencial Teórico da Proposta Pedagógica}

Tomando por base os escritos de Piaget (1973), diversos autores defendem a importância da interação nos processos educacionais (PRIMO, 2003; NEVADO, MAGDALENA, COSTA, 2002; NEVADO, CARVALHO, MENEZES, 2007; BEHAR, 2009, 2013; BECKER, 2012), o que coaduna com as ideias deste artigo.

Ao utilizar a abordagem conceitual construtivista-interacionista de Jean Piaget, especificamente o conceito de cooperação, compreende-se que as relações entre docentediscente e discente-discente se constroem fundamentadas no respeito mútuo, na reciprocidade e nas interações cooperativas.

Piaget (1973)enfatiza que as trocas interindividuais baseadas na cooperação representam o mais alto nível de socialização, envolvendo discussões e trocas de pontos de vista, implicando igualdade de direito e autonomia, assim como reciprocidade entre personalidades diferentes.Nesse sentido, ao planejar estratégias pedagógicas, o professor deve pensar em recursos que potencializem a comunicação virtualentre os membros, o que pode levar à cooperação, ou seja, a "operações efetuadas em comum ou em correspondência recíproca" (idem, p. 22).

Embora o docente seja o responsável por elaborar estratégias que suscitem interações interindividuais cooperativas, tanto o professor quanto os alunos são responsáveis pela dinâmica do grupo e pela construção do conhecimento. Nesse sentido, Nevado, Magdalena e Costa (2002) enfatizam que a interação é condição necessária a essa construção, o que inclui, além da interação com os objetos, a interação com outros sujeitos ${ }^{10}$.Portanto, as interações cooperativassão fundamentais para se pensar em propostas pedagógicas baseadas na troca contínua de experiências e saberes/conhecimentos advindos da prática docente.

Veja-se a seguir a descrição da proposta.

${ }^{9}$ Assumiu esta função entre os anos de 2005 a 2010.

${ }^{10}$ Para Piaget existem dois tipos de interação: individual (sujeito-objeto) e interindividual (sujeito-sujeito). 


\subsection{Proposta Pedagógica para o Módulo Integrador Prática Docente Supervisionada}

A figura 2 (mapa conceitualII)descreve a propostapedagógica para o módulo integrador de Prática Docente Supervisionada, cujo eixo central foi os fóruns (socializadores e de conteúdo). Ainda que as demais atividades não fossem o objeto de estudo deste artigo (portfólios), foram descritas como meio de estruturar todas as atividades propostas.

FIGURA 2 - Mapa conceitual II

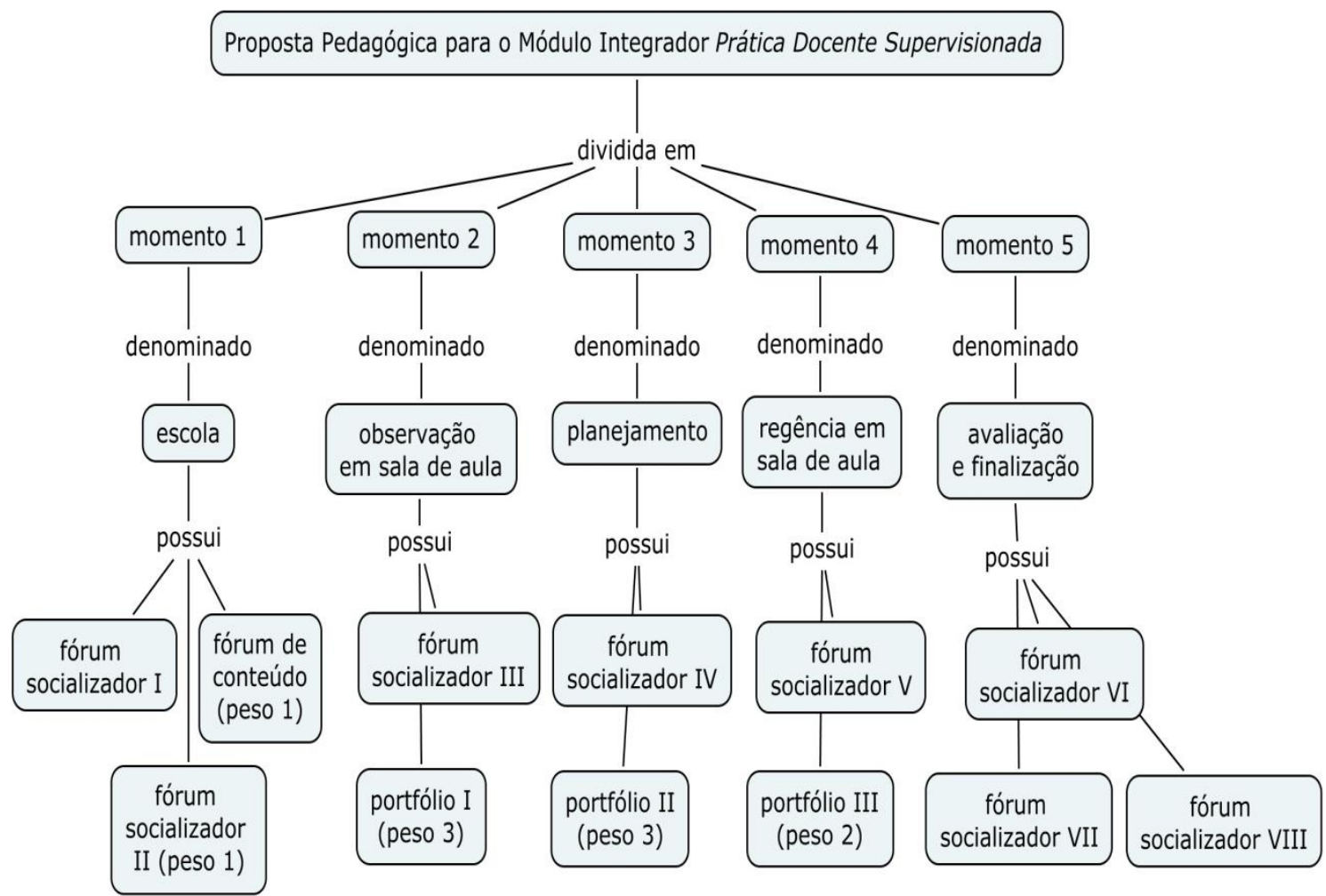

FONTE - Elaborado pela própria autora

De acordo com a figura 2, em todos os momentos houve uma atividade comum, que foi os fóruns socializadores. Eles foram criados com a finalidade de socializar as dúvidas que fossemaparecendo no decorrer da prática docentee evitando possíveis divergências que pudessem surgir, tais como: repetição de respostas e desencontros de informações entre alunos-professores, o que facilitou a cooperação e a colaboração interindividual.

Para cada momento, houve um ou mais fóruns socializadores (momentos 1 e 5, respectivamente), o que demonstrou a importância de compartilhar e socializar com o outro seus sucessos e insucessos. Segundo Nevado, Magdalena e Costa (2002, p.53), "as relações cooperativas pressupõem uma descentração do pensamento no sentido de haver uma 
coordenação entre diferentes pontos de vista (diferentes ideias), discussão, controle mútuo dos argumentos, etc".

No momento 1 , o fórum socializador I foi referente ao termo de autorização, arquivopostado no ambiente, em que os alunos-professoresdeveriampreencher com as informações da escola, bem como coletar a assinatura do (a) diretor (a) da escola onde a prática docente seria realizada. Em seguida, o arquivo preenchido deveria ser enviado pelo correio à professoratutora do módulo, ficando sob sua responsabilidade até a finalização do módulo. Não era uma exigência da FGF, mas a preferência é que a Prática Docente Supervisionada fosse realizada numa escola da rede pública (municipal ou estadual).

O preenchimento desse documento causou várias dúvidas aos alunos-professores, sendo necessário um fórum específico para saná-las. Esse fórum teve 97 participações e os alunos se ajudavam entre si, pois muitos deles escolheram a mesma escola e algumas informações coincidiram. Embora essa atividade não fosse pontuada, os alunos-professores se sentiram responsáveis por participar e colaborar com as incertezas dos colegas. Ainda nesse momento, foi criado outro fórum socializador, o II, no qual foram discutidas informações gerais da escola.

Foi solicitado aos alunos-professores que fizessem um levantamento sobre a escola, o que demandou tempo do aluno-professorpara as atividades do módulo. Esse fórum foi pontuado com peso 1 para a avaliação virtual e teve 66 participações. Criou-seum terceiro fórum, intitulado fórum de conteúdo, que versava sobre as concepções de ensino-aprendizagem, em que foram discutidas as vantagens e desvantagens de se implantar em sala de aula uma metodologia de trabalho que correspondesse às diferentes concepções (tradicional e progressista). Os alunos-professores deveriam levar em consideração aspectos como: conceitos de ensinar e aprender, papéis do aluno e professor, definição de "erro" e sistemas de avaliação.Esse fórum teve peso 1 e totalizou105 participações. Ressalta-se que não houve atividade de Portfólio no momento 1.

No momento 2, o fórum socializador III foi designado para as dúvidas sobre a observação em sala de aula. O aluno-professor observaria a prática docente de outro professor na área do seu curso e coletaria as informações solicitadas no roteiro de observação, disponibilizado na ferramentaAtividade. Em seguida, todos apresentariamdúvidas, sugestões de itens a serem observados (e que não estavam elencados no roteiro), e forneceriam ajuda aos colegas, caso houvesse alguma dificuldade na observação. O fórum não teve pontuação e totalizou 115 participações.

A atividade de Portfólio do momento 2possuiu peso 3 e solicitava que os alunos respondessem todos os itens do roteiro os quais eram referentes à escola (histórico; aspectos físicos; cronograma escolar anual; recursos humanos, tais como o núcleo gestor, pedagógico, equipe de docentes, pessoal técnico e de apoio, quantidade de alunos; bem como o trabalho com as prerrogativas da Lei de Diretrizes e Bases da Educação Nacional no 9394/96) e algumas questões específicas sobre a prática do professor observado.

A ideia de observar a prática de outro professor permitiriaao aluno-professor identificar e descrever a postura do professor a ser observado frente à concepção de ensino e aprendizagem abordada por este. Permitiria também elencar que competências (conhecimentos, habilidades e 
atitudes $)^{11}$ o professor deve possuir diante a diversidade de eventos que acontecem em uma aula.Todo o conteúdo coletado suscitaria dois momentos ao aluno-professor: descrição e reflexão. Descrever a prática de outro professor, mas também refletir sobre uma ação que não é sua, mas que pode ser tomada para si.

Reitere-se que o momento de observaçãoexige uma análise atenta do que vai ser observado, assim como capacidade de concentração, paciência, espírito alerta e sensibilidade de perceber o que comumente não se percebe, pois só é possível fazer inferências e conclusões acerca do objeto cognoscível/ cognoscente (expressão utilizada por Jean Piaget) quando se tem um planejamento do que realmente se vai observar, daí a necessidade de elaborar um roteiro de observação, pois é humanamente impossível observar todos os eventos e ao mesmo tempo.

No momento 3,0 fórum socializador IV foi designado para as dúvidas referentes à elaboração dos planos de aula.Esse fórum teve 61 participações e não foi pontuado para a nota da sala virtual. A atividade de Portfólio teve peso 3, e os alunos deveriam elaborar e enviar os planos até o último dia do momento 3. O planejamento deveria ocorrer em comunhão com o professor de sala e, em seguida, passar pela supervisão da professora-tutora do módulo.

Destaque-se que a atividade de planejar é inerente às ações do professor. Longe do que se pensa, planejar não é uma atividade apenas para quem está iniciando alguma atividade, tendo em vista que é um processo que exige organização, sistematização, previsão, decisão e outros aspectos que possam garantir o sucesso de uma ação.O momento de planejar seria muito mais um momento de expor a sua forma de fazer, o que levaria o aluno-professor a uma possível revisão e adequação de seu planejamento, exigindo uma reflexão mais detalhada sobre o objeto cognoscente. Essa reflexãodiz respeito às opções e ações do professor, ou seja, a uma programação das ações docentes e, também a um momento de pesquisa, participação coletiva e reflexão conjunta com o grupo. É importante deixar claro que o planejamento seria individual, instante em que cada um se pronuncia, toma posição e traz, posteriormente, para o conjunto a riqueza do seu pensamento, do seu querer fazer.

No momento 4 , o fórum socializador $V$ foi indicado para as dúvidas referentes à regência das aulas. Esse fórum não foi pontuado e teve 58 participações. A atividade de portfólio possuiu peso 2, e o aluno-professor deveria relatar as impressões do professor e dos alunos de sala, seus sentimentos pessoais sobre o momento vivido e uma autoavaliação sobre as aulas regidas. Freire (1996) enfatiza que esse é um momento em que o professor pode se perceber como ser inacabado, inconcluso, crítico, dialógico, autônomo e de intervenção.

No momento 5, o fórum socializador VI foi designado para tirar as dúvidas referente à elaboração do memoriale teve 56 participações. Foi postado na ferramenta Atividade o roteiro do que deveria conter cada parte do memorial. Integrado a reflexão da prática, os alunosprofessores deveriam relacionar com os autores discutidos ao longo do módulo, bem como outros que julgassem necessário.

Finalizado o memorial, o mesmo deveria ser enviado àFGF. Depois de lido pela professoratutora, o documento foi arquivado nas pastas individuais de cada aluno, sendo esta uma exigência da instituição.Ofórum socializador VII versou sobre a avaliação global do módulo,

${ }^{11}$ Segundo Perrenoud (2000), o conceito de competência engloba esses três elementos. 
totalizando 20 participações. Ofórum socializador VIII dizia respeito ao momento final na escola. Esse fórum teve 16 participações, e os alunos-professores relataram a sua saída da escola, os momentos finais com os alunos, com o professor de sala, a direção e os demais integrantes da escola. Nenhum dos fóruns referentes ao momento 5 foi pontuado.

Especificamente ao aspecto motivacional, no início de cada semana (sempre às segundasfeiras) eraenviada, pela ferramenta Correio, uma mensagem motivacional aos alunosprofessores. Algumas vezes, deixava-se uma reflexão junto à mensagem que fizessem refletir sobre suas ações, o motivo e a importância de estar ali cooperando e socializando as práticas realizadas. Muitos deles recebiam a mensagem de forma satisfatória, pois respondiam agradecendo e estimulando uns aos outros a trabalhar de forma semelhante em sala de aula. Os demais (talvezfossem indiferentes à metodologia adotada pela professora-tutora) não respondiam se eram ou não a favor do recebimento das mensagens.

No segundo mês do módulo, foi criado um fórum denominado café da tarde, onde os alunos poderiam conversar sobre qualquer assunto informalmente, disponibilizar seus contatos pessoais, como Orkut ${ }^{12}$, Msn, Twitter, Facebook ou marcar uma sessão de bate-papo, caso desejassem. $\mathrm{O}$ objetivo desse fórum foi estreitar as relações interindividuais estabelecidas em módulos anteriores e fortalecer os laços, podendo se estender para além do curso. Lévy (1999) afirma que as relações virtuais estão longe de serem frias e não excluem as emoções fortes, uma vez que a responsabilidade individual, a opinião pública e o julgamento não desaparecem na Internet. Esse fórum teve 27 participações, uma pontuação considerada baixa em relação aos demais fóruns.

Trabalhar o aspecto motivacional dos alunos-professores, além do que fora proposto para o módulo, é essencial porque se compreende que não só a permanência deles no ambiente virtualé importante, mas principalmente para mantê-los motivadosdurante todo o módulo. Acredita-se ainda que os objetivos dos discentes devam se assemelhar aos objetivos do professor, pois, se não há essa similaridade nos objetivos de ambos, a aula torna-se desinteressante para aquele (discente). Outros fatores (os quais não serão todos abordados aqui) influem positivamente para a motivação do aluno virtual, conforme as pesquisas de Flores (2009), Pavesi e Oliveira (2011; 2012) e Isler e Machado (2013).

Um dos fatores para que a motivação virtual permaneça viva é a presença e apostura do professor da comunidade.Se este se assume como ser integrante, dialógico, questionador e mediador das inquietações dos alunos, estes se sentem instigados e provocados a participar. Esta presença coaduna com as ideias de Moore e Kearsley (2001), Muilenburg e Berge (2001), Brito (2004) e Ventura (2009) ao discutirem uma presença docente que oriente e supervisione, masnão predomine e iniba a participação dos discentes no processo de ensino e aprendizagem.

O prazo de início e fim para cada atividade foi de cerca de vinte dias. Em relação aos fóruns, a participação de todos os alunos-professores foi imprescindível, pois a finalidade não foi apenas atribuir nota, conforme abordado no início dessa seção. Ao final de cada momento, os fóruns foram fechados, exceto o que não estava relacionado a um momento em específico,

${ }^{12} \mathrm{~A}$ rede social mais utilizada à época. 
como o fórum café da tarde, o que gerava compromisso dos alunos-professores com as atividades.

Ressalte-se que não se pode associar à crescente participação destes alunos nos fóruns a pontuação dada a cada fórum, pois os que não foram pontuados também tiveram uma quantidade acentuada de postagens. Exceto nos fóruns avaliação domódulo e momento final na escola, os demais tiverama participação da professora-tutora no direcionamento das respostas. A metodologia abordada no módulo de prática docente supervisionada, (no caso, participativa) não gerou desconforto para os alunos-professores, pois os mesmos já haviam sido seus alunos em módulos anteriores.

A média da sala virtual foi o somatório de todas as atividades realizadas, perfazendo o total máximo de 10 pontos. O memorial entregue também teve pontuação máxima de 10 pontos. Portanto, a avaliação final do módulo de Prática Docente Supervisionada foi o somatório das duas pontuações dividido por dois.

\subsection{Análise da Proposta Pedagógica segundo o referencial teórico de Jean Piaget}

Com base nos estudos de Piaget, só existe cooperação quando há disponibilidade de se colocar no lugar do outro, de socializar/compartilhar ideias de forma ordenada e harmônica. Se há regras, há ordem, respeito mútuo pelo pensamento e expressão do outro. A cooperação existe quando há objetivos em comum, reciprocidadee tomada de consciência ${ }^{13}$.Essa tomada de consciência aconteceuquando os alunos-professores entraram em contato com o objeto de conhecimento, ainda na sala de aula virtual.

As discussões nos fóruns socializadores e de conteúdo possibilitou, inicialmente, uma reflexão teórica sobre o objeto, cuja finalidade foi incentivar a reconstrução das práticas pedagógicas tomando por base os métodosde como o sujeito aprende (expositivos, dialogados, resolução de problemas, simuladores etc.).As reflexões fizeram com que eles repensassem sobre suas atuações e elaborassem novas propostas de trabalho,sempre compartilhando com o grupo suas ideias iniciais e os resultados obtidos.

Por outro lado, os memoriais reflexivos entregues ao final do módulo demonstraram que,mesmo professores com anos de experiência docente, ficaram aquém do esperado para a conclusão de um curso de formação de professores. Aquém, porque, nos relatos de cada aula, alguns alunos-professores apenas descreveram o que fora executado e não havia uma reflexão crítica ${ }^{14}$ da vivência em cada momento. Espera-seque o aluno-professorseja capaz de refletir sobre suas ações, corrigindoos erros cometidos ainda no percurso epossa reinventar, a cada aula, uma nova estratégia metodológica de aprendizagem, uma vez que a formação continuada exige articulação entre teoria (saber) e prática (saber-fazer). Isso só será possível se o sujeito

${ }^{13}$ Para Piaget existem níveis de consciência que variam do nível mais elementar ao mais complexo. Não convém detalhálos, pois fugiria do objetivo deste artigo.

${ }^{14}$ Ainda que houvesse um fórum específico para a elaboração do memorial, durante todo o módulo foi discutido que os materiais elaborados comporiam parte do memorial, bem como as reflexões obtidas em cada momento da prática supervisionada. 
aprendente, no caso os alunos-professores, se assumirem comoseres inquietos, curiosos, críticos e pesquisadores.

Uma possível ${ }^{15}$ razão para a falta de reflexão crítica nos memoriais pode ser atribuída às atividades dos módulos anteriores ${ }^{16}$. Diferente do módulo de prática docente supervisionada, nem todas as atividades propostas foram de autoria do professor-tutor responsável pelo módulo. Algumas já vinham elaboradas no material disponibilizado pela instituição e precisavam ser seguidas. Estas, por sua vez, estavam sem contextualização com a realidade vivenciada em sala de aula e sem relação entre teoria e prática, o que dificultava aos alunosprofessores discutirem entre si e com a professora-tutora suas dúvidas professorais. Ainda que existissem atividades de autoria da professora-tutora,não foram suficientes para suscitar o debate e reflexões mais aprofundadas sobre o que estava no plano de aula para cada módulo. Ressalte-se que não foram suficientes pela carga horária de cada módulo.

Uma sugestão seria atualizar o material instrucional de todoseles ${ }^{17}$, tanto na parte didática quanto na pedagógica, o que mereceria atenção especial para as atividades propostas para um curso de formação de professores em serviço. Outra sugestão seria repensara estruturação do projeto político-pedagógico dessescursos, de modo que todos os módulos possuíssem natureza teórico-prática. Provavelmente,isso oportunizariaaos alunos-professores a passagem de um nível de consciência a outro.

Destaque-se também a presença assídua e a postura mediadora da professora-tutora do módulo, cujo papel foi o de desequilibrar, no sentido piagetiano, o pensamento inicial dos alunos, pondo em dúvidasuas certezas provisórias e instigando-os a desconstruir a hipótese de que a forma como se ensina é sempre a mesma que se aprende. Ainda que os alunosprofessores não tenham atingido o nível mais complexo de tomada de consciência, eles afirmaram que o módulo "Prática Docente Supervisionada" contribuiu para sua formação e possibilitou outras reflexões para melhorar a prática docente, como são mostrados nos depoimentos ${ }^{18}$ a seguir:

\begin{abstract}
"Na longa jornada desse módulo pude concluir que nada é fechado em si, que mesmo professores com longos anos de docência podem (e devem) se atualizar cada vez mais. Queria agradecer a professora Paula pelo profissionalismo e paciência com que nos tratou até aqui, pelo retorno que sempre nos deu visando sempre a melhoria da próxima atividade. O material também muito bom e informativo e, principalmente, os fóruns onde nossas dúvidas eram todas sanadas. Sou-lhe muito grata, professora" (Aluna 1).

"Através deste módulo tive a oportunidade de vivenciar experiências imprescindíveis para a minha formação docente, que sem dúvida muito me servirão na atuação em sala de aula. Quero também agradecer a você PP, por oportunizar os fóruns onde sanamos inúmeras dúvidas sobre a realização de nosso estágio. Paula Patrícia você é uma tutora dedicada obrigada por sanar minhas dúvidas quanto às atividades desenvolvidas, sempre me dando sugestões, e apontando um direcionamento para a realização das mesmas.
\end{abstract}

\footnotetext{
${ }^{15}$ Possível porque não foi elaborado um instrumento de avaliação para diagnosticar com precisão as razões da falta de reflexividade crítica nos memoriais.

${ }^{16}$ Conforme dito na seção anterior, a professora-tutora já havia atuado nesta função, e com esta turma, em módulos anteriores.

${ }^{17}$ De acordo com a coordenação atual do Núcleo de Educação a Distância (NEAD - FGF), os módulos começaram a ser atualizados em 2014.2.

${ }^{18}$ Foram mantidas como no original, com erros ortográficos e de concordância. Conforme mencionado, houve um fórum específico para a avaliação do módulo e, esses depoimentos foram extraídos deste fórum.
} 
Sempre pontual, nunca deixando sem resposta. (...) Muito Obrigada por tudo!!! (Aluna 2).

"De modo geral, este foi o módulo mais interessante e dinâmico de todos os que eu fiz...adorei poder concluí-lo e quero agradecer a professora PP por ter sido tão presente, justa, e rápida com as respostas de minhas dúvidas. Foi realmente um módulo muito bem organizado que proporcionou um grande conhecimento para minha vida profissional" (Aluna 3).

"Este módulo foi muito importante para colocarmos em prática as nossas idéias e ao mesmo tempo se interar com a escola, professores e alunos. Me senti muito bem tanto no ambiente escolar quanto na sala virtual, pois a Professora PPestava sempre atenta às nossas dúvidas, nos auxiliando com muita agilidade. PP agradeço de coração toda a sua atenção depositada em seus alunos, que mesmo distante é possível sentirmos tão perto a presença do professor. Um grande abraços. E que Deus esteje sempre te iluminando para que continue atentendo as necessidades de seus alunos, contribuindo para a formação de professores capazes de seguir o seu caminho com muito amor e sabedoria" (Aluna 4).

"Prezada Professora, quero parabenizá-la pelo seu profissionalismo durante o módulo, estou muito satisfeita com as suas orientações, pois foram ótimas, claras e fundamentais para o desenvolvimento das atividades propostas. Tenho muito que agradecer pelo que estou desenvolvendo e amadurecendo e com o que posso ainda colocar em prática em meus futuros desafios na vida profissional, com o aprendizado que obtive durante o módulo" (Aluna 5).

"[...].O fato de estarmos em contato permanente com a escola é de grande importância e torna o nosso trabalho verdadeiro, pois estamos dentro da realidade da escola. A professora tutora Paula demonstrou ser muito segura em suas orientações, sendo rigorosa para que as atividades fossem cumpridas dentro do estabelecido, isso faz com que todos que estejam envolvidos também demonstre compromisso com os estudos. Foi um módulo que desenvolveu um crescimento e maturidade aos estudos!!!" (Aluna 6).

Infere-se, com base nos relatos transcritos, que os fóruns atingiram o objetivo que foi o de compartilhar interesses, experiências, dúvidas e motivar os alunos, conforme explicitado na seção4.2. Verifica-se também que o fórum pode ser compreendido como ferramenta de desenvolvimento pessoal e interpessoal, de investigação e de formação. Daí a importância de se estruturar uma proposta pedagógica de acordo com a realidade dos alunos-professores e de elaborar estratégias diversificadas de aprendizagem que visem responder as suas expectativas. Um fator fundamental para o êxito desse módulo foi a linguagem utilizada pela professoratutora, caracterizada como clara, de fácil entendimento e sem contradições, gerando segurança para os alunos-professores.

Segundo Silva (2012a, p. 112), "o fórum é a interface mais utilizada, a mais estudada e a que mais créditos recebe como ambiente que contempla compartilhamento, registro, interlocução e colaboração", ambiente favorável à avaliação dialógica e democrática, uma vez que funciona como arena de debate, negociação e construção coletiva que permite o acompanhamento e registro de cada componente e suas contribuições com a tarefa. 


\section{5 (In) Conclusões}

Ao descrever a proposta adotada um ponto merece destaque: as estratégias didáticopedagógicas utilizadas pela professora-tutora, que suscitaram as trocas comunicativas (oriundas do processo de socialização), itens que se relacionam entre si.

As estratégias tiveram como elemento central o compartilhamento de saberes, práticas, dúvidas e até mesmo do desconhecido, fazendo com que os alunos-professores se reconhecessem como seres de relações, externalizando seus conhecimentos, subjetividades e escolhas, confrontando-as com a realidade vivenciada (como docentes e discentes).

A utilização do fórum virtual, como atividadepredominante na proposta, mostrou-se eficaz por vários motivos: por enfatizar uma troca comunicativa contínua e possível de modificação. Essa troca não se deteve exclusivamente a epistemologia do conhecimento (organizado e sistematizado), mas a todo tipo de informação (formal e informal). A diversidade e o fluxo constante de pensamento construído em conjunto possibilitou romper com a ideia de aprendizagem linear, de um pensamento único e "verdadeiro" (até que um novo saber fosse construído). As identidades (percepções) foram constantemente (re) construídas, uma vez que o processo de socialização permitiu que as identidades estivessem em movimento, sendo a socialização o elemento chave para reconhecer-se membro de uma determinada cultura, no caso " a cultura online" (arraigada de princípios específicos), bem como sobre a cultura do outro.

Ainda que as atividades fossem específicas para uma determinada cultura (instituição particular, professores em serviço e de diferentes áreas do saber e suportes telemáticos específicos, conforme descrito na seção 4), acredita-se que em outros contextos semipresenciais a metodologia utilizada possa ser replicada. Isso vai depender do objetivo maior a ser alcançado e da modalidade que o curso é ofertado (presencial, semipresencial ou totalmente a distância). Daí a necessidade de um planejamento flexível, de familiaridade e aprofundamento teórico com o objeto a ser trabalhado.

Como contribuição, a proposta pedagógica mostrou alternativas positivas de serem trabalhadas com professores em serviço, tais como: a desconstrução das certezas professorais (do fazer docente), através da socialização das práticas e do conhecimento teórico-prático das interações interindividuais; o incentivo à pesquisa, possibilitando o aluno-professor a (re)pensar os métodos de ensino utilizados; o exercício da autoria e co-autoria, incentivando a valorização das ideias discentes e, sobretudo, os processos avaliativos num curso semipresencial, desmistificando a ideia de que só há interesse por parte do discente quando há atribuição de nota.

Ao articular os conhecimentos prévios dos alunos-professores com os significados construídos em conjunto, percebeu-se uma articulação entre suas experiências pessoais e profissionais, o que foi construído em conjunto e a expropriação hierárquica do saber, ponto favorável a idealização de abordagens metodológicas emergentes e complexas. Ainda assim, há necessidade de maior investigação no que tange à adoção de outras estratégias que auxiliem formalmente quanto ao uso de métodos de ensino na modalidade semipresencial. O importante 
quando se utilizam determinadas propostas, é privilegiar a problematização, a cooperação eos saberes construídos em conjunto, todos eles fundamentados em uma concepção epistemológicaprogressista de educação.

\section{Referências}

BEHAR, Patricia Alejandra.As novas tecnologias da informática e das comunicações e o novo modelo educacional.Disponível em: <HTTP://www.nuted.ufrgs.br/oficinas/criacao/patricianovastecnologias.doc>. Acesso em: 01 jun. 2016.

BEHAR, Patricia Alejandra (org.). Modelos pedagógicos em educação a distância. Porto Alegre: Artmed, 2009.

Penso, 2013.

Competências em educação a distância. Porto Alegre:

BECKER, Fernando. Educação e construção do conhecimento. 2 ed. Porto Alegre: Penso, 2012.

BRASIL. Ministério da Educação, Cultura e Desporto (MEC). Decreto no 5622/2005. Disponível em: <portal.mec.gov.br/seed/arquivos/pdf/dec_5622.pdf>. Acesso: 01 jun. 2016.

- Lei de diretrizes e bases da educação nacional no 9394/96. Disponível em: <portal.mec.gov.br/arquivos/pdf/ldb.pdf>. Acesso em: 01 jun. 2016.

BRITO, Vivina. El foro electrónico: uma herramienta tecnológica para facilitar elaprendizaje colaborativo. Edutec-e.Revista Electrónica de Tecnologia Educativa.Espanha;v.1; n.17; mar.2004.

BRYM, Robert. et al. Sociologia: sua bússola para um novo mundo. São Paulo: Thomson Learning, 2006.

CHIZZOTTI, Antonio. Pesquisa qualitativa em ciências humanas e sociais. 6 ed. Petrópolis: Rio de Janeiro, Vozes, 2014.

FACULDADE INTEGRADA DA GRANDE FORTALEZA (FGF). Como funcionam os cursos?. Disponível em: http://www.nead.fgf.edu.br/default.aspAcesso em: 23mar. 2016.

FLORES, Angelita Marçal. O feedback como recurso para a motivação e avaliação da aprendizagem na educação a distância.In: $15^{\circ}$ Congresso Internacional ABED de Educação a Distância, Fortaleza (CE), 2009.

FREIRE, Paulo. Pedagogia da autonomia: saberes necessários à prática educativa. São Paulo: Paz e Terra, 1996. 148p.

GIDDENS, Anthony. Sociologia. 4ed. Porto Alegre: Artmed, 2005.

ILLERA, José Luis Rodriguez. Como as comunidades virtuais de prática e de aprendizagem podem transformar a nossa concepção de educação. Sísifo: Revista de Ciências da Educação.Lisboa,no 3. p.117-124. Mai/Ago 2007.

ISLER, Gustavo Lima.; MACHADO, Afonso Antonio. Motivação discente em cursos na modalidade à distância (EaD): fatores que influenciam. Revista NUPEM, Campo Mourão/PR, v.5, n.9, P.67-84. jul./dez., 2013.

KENSKI, Vani Moreira.Tecnologias e tempo docente. Campinas: Papirus, 2013. 171p.

LEVY, Pierre.Cibercultura. São Paulo: Ed. 34, 1999. 231p. 
MATTA, Alfredo Eurico Rodrigues. Comunidades em rede de computadores: abordagem para a Educação a Distância - EAD acessível a todos. Revista Brasileira de Aprendizagem Aberta e a Distância.(on-line). São Paulo, 2003. Disponível em:

http://www.abed.org.br/revistacientifica/Revista_PDF_Doc/2003_Comunidades_Rede_Computa dores_Alfredo_Matta.pdf Acesso: 01 jun. 2016.

MOORE, Michael; KEARSLEY. Greg. Distance educacion: a systems view. Toronto: Thomson Wadsworth, 2001. 398p.

MUILENBURG, Lin; BERGE, Zane. Barriers to distance education: a factor-analytic study. The American Journal of DistanceEducation. 15(2): 7-22, 2001.

NEVADO, Rosane Aragón de; MAGDALENABeatriz Corso; COSTA, Iris Elisabeth Tempel Costa. Formação de professores multiplicadores:nte@projetos.cooperativos.ufrgs.br. In: MORAES, Maria Cândida (org.). Educação a distância:fundamentos e práticas. São Paulo: Unicamp, 2002, p.51-60.

NEVADO, Rosane Aragón de; CARVALHO, Marie Jane Soares; MENEZES, Crediné Silva de. Aprendizagem em rede na educação a distância. Porto Alegre: Ricardo Lenz, 2007.

PAVESI, Marilza Aparecida; OLIVEIRA, Diene Eirede Mello Bortotti. Motivação do aluno na educação a distância. IX ANPEd Sul. Seminário de Pesquisa em Educação da Região Sul, 2012. Disponível http://www.portalanpedsul.com.br/admin/uploads/2012/GT16_Educacao,_Comunicacao e T ecnologias/Trabalho/03_19_30_GT_16_-_Marilza_Aparecida_Pavesi.pdf Acesso em: 01 jun. 2016.

Qual o lugar da motivação nas pesquisas sobre EaD?In: X Congresso Nacional de Educação - Educere e I Seminário Internacional de Representações Sociais, Subjetividade da Educação - SIRSSE. Curitiba: PUC, 2011. 6282-6295p.

Disponível em: http://educere.bruc.com.br/CD2011/pdf/5408_3156.pdf Acesso em: 01 jun. 2016.

PERRENOUD, Philippe.Dez novas competências para ensinar:convite à viagem. Porto Alegre: Artmed, 2000. 192p.

PIAGET, Jean. Estudos sociológicos. Rio de Janeiro: Forense, 1973. 233p.

PRIMO, Alex Fernando Teixeira. Interação mediada por computador: a comunicação e a educação a distância segundo uma perspectiva sistêmico-relacional. 2003. 291p. Tese (Doutorado em Informática na Educação). Universidade Federal do Rio Grande do Sul, Porto Alegre, 2003.

SILVA, Sandra Gonçalves da. Fórum educacional digital: dialogismos e construção do conhecimento.2009. 161p. Dissertação (Mestrado em Língua Portuguesa).Pontifícia Universidade Católica de São Paulo, São Paulo, 2009.

SILVA, Marco. Educação a distância (ead) e educação on-line (eol) nas reuniões do gt16 da anped (2000-2010).Revista Teias. v.13, n.20, p.95-118, set/dez.2012a. Disponível em: <http://www.periodicos.proped.pro.br/index.php/revistateias/article/view/1362>. Acesso em: 01 jun. 2016.

Paulo: Loyola, 2012b.

Sala de aula interativa: educação, comunicação, mídia clássica. 6 ed. São

TAVARES, Romero. Construindo mapas conceituais.Revista Ciências \& Cognição 2007; Vol 12: 72-85. Diponível em: http://www.cienciasecognicao.org/pdf/v12/m347187.pdf Acesso em: 01 jun. 2016. 
VENTURA, PaulaPatríciaBarbosa. Comunidades de aprendizagem em cursos a distância: investigando as relações sociais em ambientes virtuais.2009. 153p. Dissertação (Mestrado em Educação). Universidade Federal do Ceará. Faculdade de Educação. Fortaleza, 2009.

Submetido para avaliação em 23 de março de 2016

Aprovado para publicação em 27 de setembro de 2016

\section{Paula Patrícia Barbosa Ventura}

Professora Efetiva do Instituto Federal de Educação, Ciência e Tecnologia do Ceará (IFCE). Doutoranda em Educação pelo Programa de Pós-Graduação em Educação - Universidade Federal do Ceará - UFC, Brasil, paula.ventura@ifce.edu.br 